\title{
Chapter 1 \\ The Use of Be-7 as a Soil and Sediment Tracer
}

\author{
A. Taylor, W. H. Blake, A. R. Iurian, G. E. Millward and L. Mabit
}

\subsection{Origin and Agro-Environmental Behaviour of ${ }^{7} \mathrm{Be}$}

\subsubsection{Atmospheric Production of ${ }^{7} \mathrm{Be}$}

Beryllium-7 $\left({ }^{7} \mathrm{Be}\right)\left(\mathrm{T}_{1 / 2}=53.3\right.$ days $)$ is a cosmogenic fallout radionuclide (FRN) produced in the upper atmosphere by cosmic ray spallation of nitrogen and oxygen. As reported by Kaste et al. (2002), rates of production are dependent upon solar activity with greater production in the stratosphere than the troposphere and generally increased production occurring at higher latitudes owing to cosmic ray deflection towards the poles.

Following its formation, ${ }^{7} \mathrm{Be}$ becomes associated with aerosols and its flux is then controlled by complex atmospheric transport processes, which display seasonal variations largely linked to atmospheric mixing and precipitation patterns. During

\footnotetext{
A. Taylor $(\varangle) \cdot$ G. E. Millward

Consolidated Radioisotope Facility (CoRiF), University of Plymouth, Plymouth, UK

e-mail: alex.taylor@plymouth.ac.uk

\section{G. E. Millward}

e-mail: G.Millward@plymouth.ac.uk

W. H. Blake

School of Geography, Earth and Environmental Sciences, University of Plymouth, Plymouth, UK e-mail: william.blake@plymouth.ac.uk
}

\author{
A. R. Iurian \\ Terrestrial Environment Laboratory, IAEA Laboratories Seibersdorf, Seibersdorf, Austria \\ e-mail: A.Iurian@iaea.org \\ L. Mabit
}

Soil and Water Management and Crop Nutrition Subprogramme, Joint FAO/IAEA Division of Nuclear Techniques in Food and Agriculture, International Atomic Energy Agency, Vienna, Austria

e-mail: L.Mabit@iaea.org 
the spring months at mid latitudes, increased stratosphere-troposphere exchange can occur during folding of the tropopause leading to higher concentrations of ${ }^{7} \mathrm{Be}$ in the troposphere (Kaste et al. 2002). Once in the troposphere, ${ }^{7} \mathrm{Be}$ is subjected to vertical mixing through convective circulation, which is likely to increase during warmer months and serves to transport ${ }^{7} \mathrm{Be}$ enriched air to the lower troposphere, increasing its availability for precipitation scavenging. Given that precipitation scavenging is the main mechanism for the removal of ${ }^{7} \mathrm{Be}$ from the atmosphere, seasonal and latitudinal climatic conditions exert a strong influence upon atmospheric concentrations (Kusmierczyk-Michulec et al. 2015).

\subsection{2 ${ }^{7}$ Be Fallout}

Wet deposition governs ${ }^{7}$ Be delivery to the Earth's surface while dry deposition only accounts for approximately $10 \%$ of the overall fallout (Kaste et al. 2002). Activity concentration of ${ }^{7} \mathrm{Be}$ in rainwater $\left(\mathrm{Bq} \mathrm{L}^{-1}\right)$ is conditional on its availability for scavenging and is influenced by a number of factors including rainfall rates and volumes (Ioannidou and Papastefanou 2006).

The term 'washout' refers to situations when rainfall scavenging exceeds the availability of ${ }^{7} \mathrm{Be}$ in the atmosphere leading to a reduction in ${ }^{7} \mathrm{Be}$ rainwater activity concentration across an event and following high magnitude or prolonged rainfall events. In contrast, greater activity concentrations during low magnitude events can be related to efficient scavenging of ${ }^{7} \mathrm{Be}$ by fine droplets where there is an abundance of ${ }^{7}$ Be-bearing aerosols (Ioannidou and Papastefanou 2006). The processes of atmospheric circulation and depletion not only affect the activity concentrations of ${ }^{7} \mathrm{Be}$ on a temporal scale, but are also likely to increase its spatial variability (Taylor et al. 2016). ${ }^{7} \mathrm{Be}$ deposition $\left(\mathrm{Bq} \mathrm{m}^{-2}\right)$ is significantly correlated to the amount of rainfall received on an event basis and, therefore, seasonal depositional fluxes reflect monthly rainfall volumes (Doering and Akber 2008).

\subsection{3 ${ }^{7}$ Be Sorption Behaviour in Soils and Sediments}

Upon deposition and infiltration into the soil surface, ${ }^{7} \mathrm{Be}$ is known to be rapidly adsorbed to fine soil particles (Fig. 1.1), which is supported by laboratory batch studies, high partition coefficients $\left(\mathrm{K}_{\mathrm{d}}>10^{5}\right)$ in aquatic systems and shallow depth distributions displayed in a range of soil types (Taylor et al. 2013). ${ }^{7}$ Be shows preferential adsorption to fine sediment fractions (Taylor et al. 2014), which are likely to be readily mobilised in hillslope systems. In solutions of $\mathrm{pH} 5-6$ and in the absence of humic acid, ${ }^{7} \mathrm{Be}$ is likely to be present as $\mathrm{Be}^{2+}$ and the hydrolysed species, $\mathrm{BeOH}^{+}$; both of these forms are highly reactive, resulting in rapid sorption rates (Kaste et al. 2002). The rapid adsorption together with a short half-life (the latter precludes the effects of diffusion and bioturbation over time) leads to distributions typically extend- 


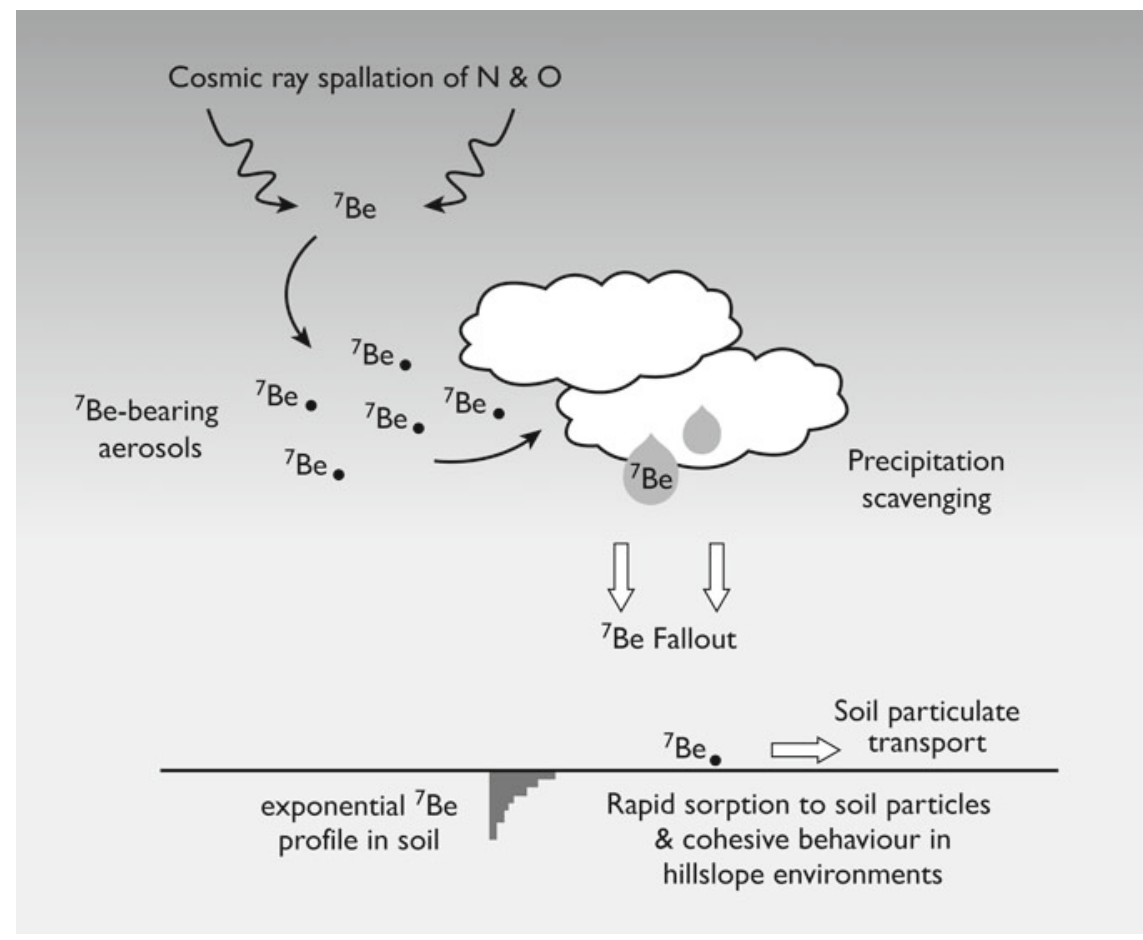

Fig. 1.1 Schematic diagram of ${ }^{7}$ Be production and fallout. ${ }^{7} \mathrm{Be}$ is produced by cosmic ray spallation in the upper atmosphere and becomes associated with aerosols. ${ }^{7}$ Be-bearing aerosols are scavenged by precipitation and, consequently, wet deposition is the dominant pathway to the Earth's surface. ${ }^{7} \mathrm{Be}$ is rapidly adsorbed to soil particles and remains cohesive under oxic field conditions

ing to around $20 \mathrm{~mm}$ below the soil surface and an exponential decrease with depth (Fig. 1.2). Where soils remain aerated and free from waterlogged conditions, as is the case in most agricultural field sites, ${ }^{7} \mathrm{Be}$ is likely to remain adsorbed to soil particles (Taylor et al. 2012). Both characteristics (i.e. rapid adsorption and cohesive behaviour) are key prerequisites for ${ }^{7} \mathrm{Be}$ application as a soil redistribution tracer.

\subsection{The Use of ${ }^{7} \mathrm{Be}$ as a Soil Redistribution Tracer}

The application of FRN tracers (e.g. ${ }^{7} \mathrm{Be},{ }^{137} \mathrm{Cs},{ }^{210} \mathrm{~Pb}$ ex, $\mathrm{Pu}$ ) provides distinct and additional advantages over traditional soil monitoring techniques by enabling retrospective estimates of soil redistribution from relatively few site visits. Through carefully planned sampling programmes, high spatial resolution estimates of soil redistribution can be acquired, which are unlikely to be achieved using conventional methods (Walling et al. 1999). In this regard, the use of nuclear and iso- 
Fig. 1.2 Example of ${ }^{7} \mathrm{Be}$ depth distribution in a clay loam soil in Seibersdorf, Austria (Iurian et al. 2013). Note that the ${ }^{7} \mathrm{Be}$ depth distribution is plotted as a mass depth $\left(\mathrm{kg} \mathrm{m}^{-2}\right)$ and the metric depth $(\mathrm{mm})$ is shown here only for comparison. The use of mass depth provides a more precise and accurate measure of depth in the context of soil redistribution studies. Calculation of areal inventory $\left(\mathrm{Bq} \mathrm{m}^{-2}\right)$ is covered in Chap. 2

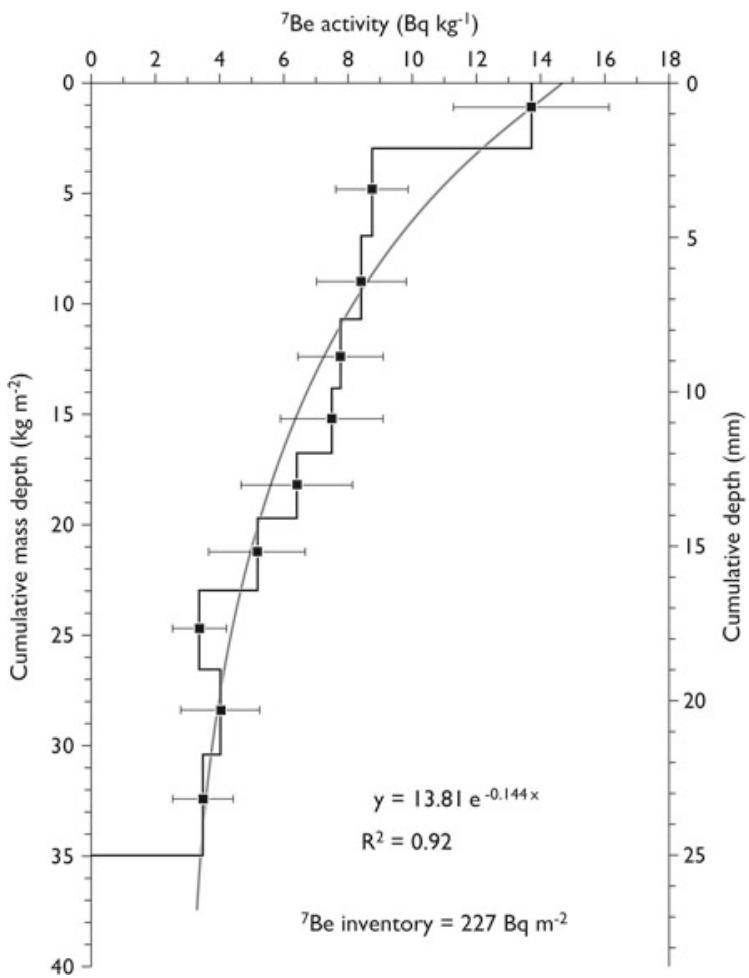

topic techniques enables rigorous assessment of soil conservation measures and, if applied over extended time periods, can help to determine the sustainability of agricultural systems.

FRN tracing techniques have been commonly applied to assess soil redistribution at the hillslope scale using ${ }^{137} \mathrm{Cs}\left(\mathrm{T}_{1 / 2}=30.2\right.$ years $)$ and ${ }^{210} \mathrm{~Pb}\left(\mathrm{~T}_{1 / 2}=22.3\right.$ years $)$. The half-life of these radionuclides enables redistribution estimates relating to mediumterm (i.e. decadal) timescales, providing important information with regard to soil loss or gain in an historical context. However, the application of these decadal-scale radionuclides does not allow for determination of soil redistribution as a result of recent changes in land use or recent rainfall events. This is an important consideration given the need for assessment of soil conservation measures with increasing recognition of soil as a finite global resource. The short-lived ${ }^{7} \mathrm{Be}$ is, therefore, complementary to the other FRN tracers in enabling estimates of soil redistribution across much shorter timescales such as rainfall events or wet seasons.

The premise for using ${ }^{7} \mathrm{Be}$ as a soil redistribution tracer is that the tracer will be rapidly adsorbed to soil particles upon fallout, thus establishing an inventory $\left({ }^{7} \mathrm{Be}\right.$ activity per unit area) $\left(\mathrm{Bq} \mathrm{m}^{-2}\right)$ at a sampling site. A key assumption of the technique is that ${ }^{7} \mathrm{Be}$ will remain adsorbed to soil particles across the timescale of the study and, therefore, any changes in inventory (i.e. depletion or gain) at a sampling point can 
only occur as a result of fallout, radioactive decay and/or soil redistribution processes. The ${ }^{7} \mathrm{Be}$ inventory at a site, which experiences soil redistribution, can be compared directly to the ${ }^{7} \mathrm{Be}$ inventory at a stable location, referred to as a reference site, where there is no loss or gain in inventory as a result of soil redistribution. The inventory at a reference site is established only through ${ }^{7} \mathrm{Be}$ atmospheric fallout and, given that this is predominantly delivered by precipitation, reference sites are typically level areas which retain the fallout without loss except for radioactive decay. Alongside the important tracer assumptions of rapid adsorption upon fallout and cohesive behaviour during the period of study, it is also crucial that the reference site receives the same fallout deposition as the eroding area of interest, which requires both sites to be in close proximity. In addition to this, it is also assumed that the fallout received at the study site will be uniform so any differences in inventory across the study area can be attributed to soil redistribution. If these assumptions hold, then any reduction in inventory at a sampling location with respect to the reference inventory can be attributed to soil loss and a gain in inventory would suggest soil deposition, given that the redistribution of ${ }^{7} \mathrm{Be}$ (as a cohesive tracer), will only occur in line with movement of the sediment to which it is adsorbed.

To quantify the mass of soil eroded or deposited $\left(\mathrm{kg} \mathrm{m}^{-2}\right)$, it is essential to determine the depth distribution of ${ }^{7} \mathrm{Be}$ in the soil profile and, in particular, the relaxation mass depth (referred to as $h_{0}$ ) a value, which describes the shape of the ${ }^{7} \mathrm{Be}$ distribution. This is an essential component of the commonly applied soil redistribution model described below. On the basis of this, any change in ${ }^{7} \mathrm{Be}$ inventory at a sampling location can be fitted to the mass of soil redistribution required to implement that change. An example is given in Fig. 1.3, which shows a loss of $100 \mathrm{~Bq} \mathrm{~m}^{-2}$ at the eroded location (i.e. inventory of $300 \mathrm{~Bq} \mathrm{~m}^{-2}$ ) with respect to the stable reference inventory (i.e. $400 \mathrm{~Bq} \mathrm{~m}^{-2}$ ). By establishing the exponential shape of the ${ }^{7} \mathrm{Be}$ profile, the conversion model is able to estimate the mass depth of soil required to reduce the inventory by $100 \mathrm{~Bq} \mathrm{~m}^{-2}$.

The specific conversion model used to derive soil redistribution magnitudes (Profile Distribution Model [PDM]) is detailed in Blake et al. (1999) and Walling et al. (2009) and the basis of this is outlined in Appendix 1.1. In addition, a worked example of this model is provided in Chap. 4.

\subsection{Examples of the Application of ${ }^{7} \mathrm{Be}$ as a Soil Redistribution Tracer}

Blake et al. (1999) and Walling et al. (1999) carried out the first comprehensive investigation into the use of ${ }^{7} \mathrm{Be}$ to estimate short-term soil redistribution by studying the impact of a heavy rainfall event at an agricultural site in southwest England. The ${ }^{7}$ Be depth distributions from this study site are shown in Fig. 1.4. The key requirement of uniform ${ }^{7} \mathrm{Be}$ fallout across the study location was satisfied owing to the soil ${ }^{7} \mathrm{Be}$ inventory being reset (i.e. reduced to below detectable limits) by ploughing prior to 


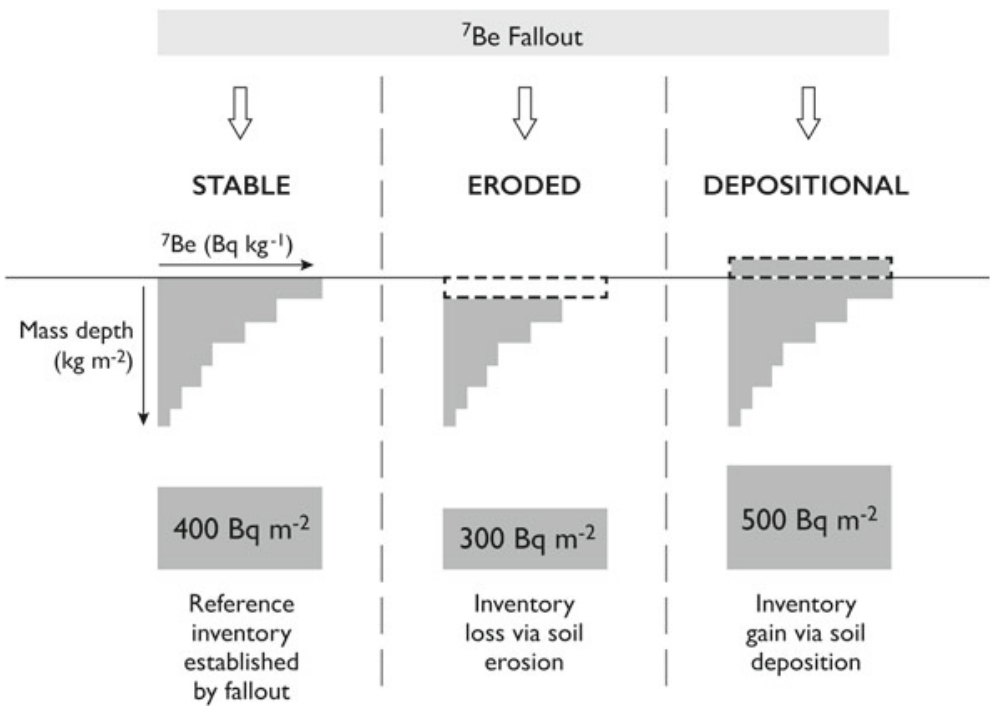

Fig. 1.3 Conceptual diagram of the premise for using ${ }^{7} \mathrm{Be}$ as a soil erosion tracer. The figure shows the ${ }^{7} \mathrm{Be}$ inventory $\left(400 \mathrm{~Bq} \mathrm{~m}^{-2}\right)$ and depth distribution at a stable reference location, which has been established by ${ }^{7} \mathrm{Be}$ atmospheric fallout. The eroded and depositional zones (representing a neighbouring hillslope area for example) have received the same fallout as the reference location, thus, an inventory has been established but the zones have experienced depletion or enhancement of the ${ }^{7} \mathrm{Be}$ inventory as a result of soil erosion and soil deposition respectively. This simplified conceptual diagram can be compared to examples of measured ${ }^{7} \mathrm{Be}$ inventories in Fig. 1.4

the commencement of the investigation. There was also a period of low intensity rainfall prior to the erosive event, which established a measurable ${ }^{7} \mathrm{Be}$ inventory without causing significant soil redistribution. A reference baseline inventory was estimated from neighbouring undisturbed pasture locations against which the slope inventories could be compared. The depth profile was determined in a non-eroded part of the study field. The PDM was used to determine soil redistribution rates and results indicated high levels of soil export from the site as a consequence of the intense rainfall event and compacted soil conditions, highlighting the pressing need for soil conservation measures to maintain soil fertility and to prevent sediment from entering catchment watercourses.

As highlighted by Mabit et al. (2014), an important advantage in the use of ${ }^{7} \mathrm{Be}$ as a soil erosion tracer is the ability to assess the effectiveness of recent soil conservation measures or the impacts of land use change. Schuller et al. (2006) applied the approach proposed by Blake et al. (1999) to document the effects of recent forest clearance upon slope soils in a timber harvesting region of Chile. Through the ${ }^{7} \mathrm{Be}$ approach, the use of mitigation strategies could be evaluated and, in this case, the need for further improvements in soil conservation strategies was identified. Sepulveda et al. (2008) aimed to assess the effects of land management practice (in this case stubble burning) by using a combined FRN approach $\left({ }^{7} \mathrm{Be}\right.$ in conjunction with 
(a)

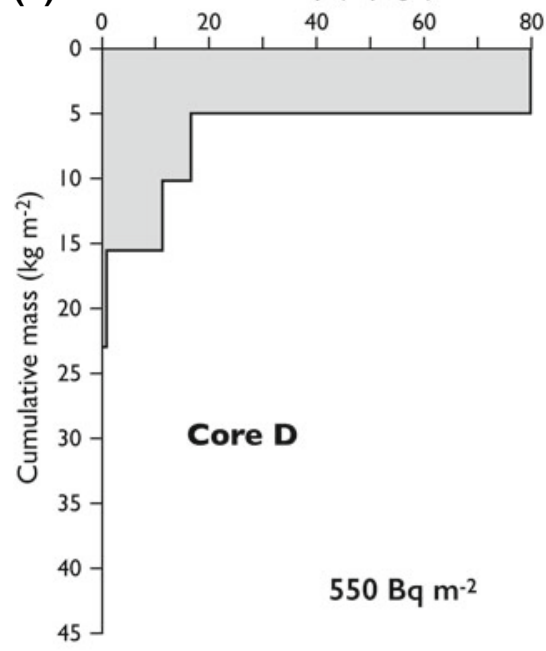

(c)

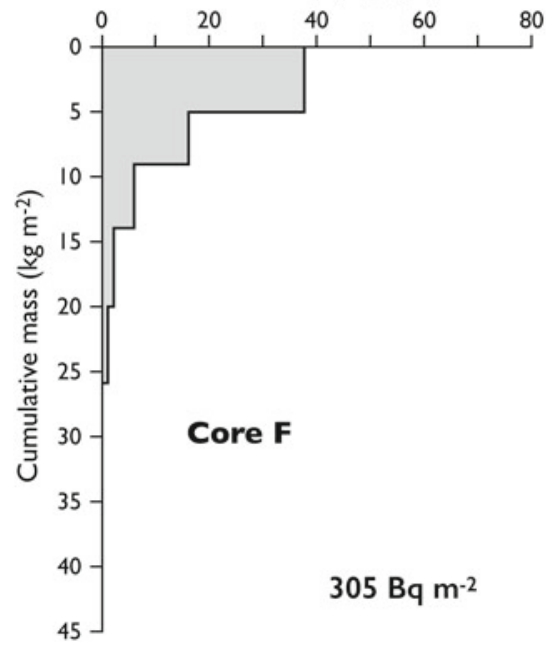

(b)

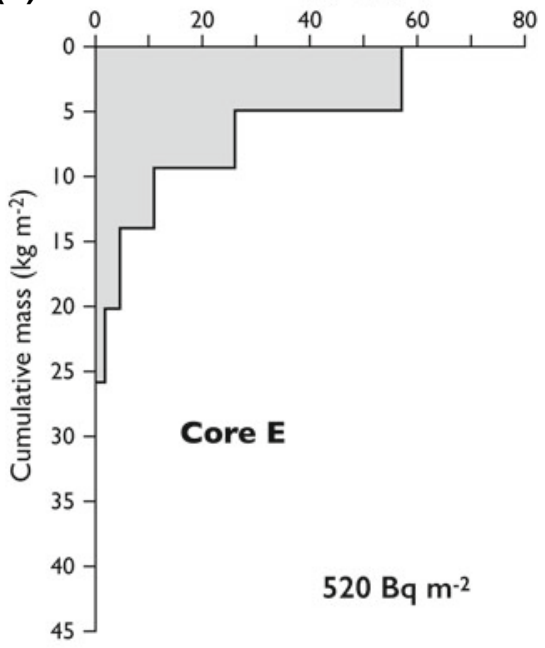

(d)

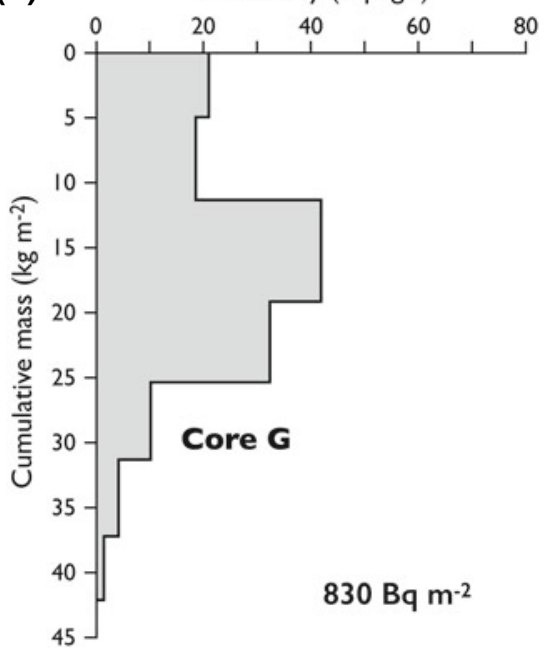

Fig. 1.4 ${ }^{7}$ Be depth distributions at a stable reference location (a), eroded hillslope locations (b and c) and a depositional hillslope location (d) [based on Walling et al. (1999)]. Note the depleted ${ }^{7} \mathrm{Be}$ inventories at the eroding sites and the increased inventory at the depositional site with respect to the reference location 
$\left.{ }^{137} \mathrm{Cs}\right)$. Here, the combined use of FRNs was able to compare impacts associated with different land management scenarios across a range of timescales, providing key information with regard to the sustainability of the agricultural system. Blake et al. (2009) also applied a combined approach and used ${ }^{7} \mathrm{Be}$ in conjunction with ${ }^{137} \mathrm{Cs}$ and ${ }^{210} \mathrm{~Pb}$ to determine post wildfire sediment budgets at hillslope sites in southeast Australia. Data identified major sediment source areas and focussed attention on the implications of wildfire for water quality management.

Blake et al. (1999) and Sepulveda et al. (2008) identified the occurrence of extreme erosion events by comparing short term erosion rates with medium-term estimates derived from ${ }^{137}$ Cs. Walling et al. (1999) showed that medium-term erosion rates at the study site were approximately 5 times lower than the short-term rates, suggesting that the studied rainfall event may not have been representative of seasonal patterns in rainfall. Owing to this, adjustments to the model were suggested by Walling et al. (2009) to enable the PDM to be applied across a greater timescale, encompassing a number of erosive rainfall events and improving representativeness. Thus, a method was developed for extending the use of the PDM to periods covering a few months or wet seasons. Within this extended timescale approach, the fundamental aspects of the model remain similar to the conventional approach whereby ${ }^{7} \mathrm{Be}$ inventories at a sample point are compared to a reference baseline and the depth distribution of ${ }^{7} \mathrm{Be}$ is measured. However, for the approach to be applied across multiple erosive rainfall events it is crucial to consider changes in the ${ }^{7} \mathrm{Be}$ inventory across the study period to avoid underestimation of erosion rates. Additional components of the model are, therefore, included whereby loss of inventory at a sampling point is accounted for by estimating the relative erosivity of each rainfall event and ongoing radioactive decay. Similarly, assessment of inventory gain accounts for additional ${ }^{7} \mathrm{Be}$ fallout during the study period alongside soil redistribution. The application of this modified approach was piloted by Schuller et al. (2010), with soil conservation measures shown to be less effective across an extended time period, which encompassed a range of rainfall events, demonstrating the value of considering soil erosion in a long-term context.

Recent plot studies have validated the method on a site-specific basis by demonstrating comparability between the ${ }^{7} \mathrm{Be}$-derived soil redistribution budget and direct measurements (e.g. Porto and Walling 2014; Shi et al. 2011).

\subsection{The Requirement for a Standardised Approach}

FRN tracers are likely to be used in a wide range of environments to assess soil redistribution and, as such, numerous methodological approaches for establishing the key model parameters have been applied. Although it is necessary to tailor sampling approaches to local environmental conditions, it is also important that the approach is standardised, as far as is practicable, to ensure data quality and aid comparability (Mabit et al. 2008).

${ }^{7} \mathrm{Be}$ has the potential to be a valuable decision support tool for catchment managers although to achieve robust estimates of soil redistribution using the PDM it is crucial 
to accurately estimate its key parameters namely:(1) the reference ${ }^{7} \mathrm{Be}$ inventory, and (2) the ${ }^{7} \mathrm{Be}$ depth distribution (the latter to ensure an accurate value of $h_{0}$ ). It is also important to consider whether the selective transport of particle size fractions is occurring during rainfall events given preferential association of ${ }^{7} \mathrm{Be}$ to fine soil fractions $(<63 \mu \mathrm{m})$. Failure to account for preferential adsorption to fine particles can lead to overestimation of soil erosion rates since a large proportion of the ${ }^{7} \mathrm{Be}$ inventory is associated with the fine sediment fractions, which are likely to be readily mobilised during rainfall events. Hence a relatively large deficit in ${ }^{7} \mathrm{Be}$ inventory could actually equate to a low mass of soil loss.

The requirement for standardising procedures is of particular importance for determining ${ }^{7} \mathrm{Be}$ depth distributions in light of recent studies, which demonstrate how the choice of sampling method can influence results (Baumgart et al. 2016; Ryken et al. 2016). Determining ${ }^{7} \mathrm{Be}$ depth distributions in soils is a practical challenge and one that requires careful consideration of the sampling site, both in terms of stability and uniformity (Ryken et al. 2016) as well as a precise sampling method. The latter requires a technique that allows fine depth increments $(2 \mathrm{~mm}$ depths $)$ to be collected throughout the ${ }^{7}$ Be profile enabling enough detail to be able to accurately determine $h_{0}$. Mabit et al. (2014) designed and tested a reproducible tool and a modus operandi, which permits collection of fine soil increments in a range of soil types and provides a basis for standardising the sampling method for $h_{0}$ determination.

In practice, developing a robust sampling strategy to establish model parameters and assess soil redistribution is likely to require a balance between the number of samples required to ensure data quality and the capacity for sample analysis. As with any field operations, preliminary knowledge of the agro-environmental conditions and background data (e.g. land use history; soil hydrological properties) at the sampling site is beneficial and will help to streamline a pragmatic sampling programme.

Against this background, Chap. 2 provides a guideline for undertaking a soil redistribution study using ${ }^{7} \mathrm{Be}$ as a tracer by outlining a standard approach for establishing key conversion model parameters.

\section{Glossary}

FRN

Becquerel

Activity Concentration

Inventory

Relaxation mass depth $\left(h_{0}\right)$

Cumulative mass depth
Fallout Radionuclide.

The SI unit of radioactivity.

Radioactivity per unit of volume or mass e.g. Bq $\mathrm{L}^{-1} ; \mathrm{Bq} \mathrm{kg}^{-1}$.

Radioactivity per unit area $\left(\mathrm{Bq} \mathrm{m}^{-2}\right)$ also termed areal activity.

The soil mass depth $\left(\mathrm{kg} \mathrm{m}^{-2}\right)$ at above which $63.2 \%$ of the beryllium-7 inventory can be found.

The distribution of ${ }^{7} \mathrm{Be}$ with depth in the soil profile is expressed in units of areal mass 
$\left(\mathrm{kg} \mathrm{m}^{-2}\right)$ rather than metric units $(\mathrm{mm})$. This provides a more accurate measure of depth in the context of the soil redistribution models.

Profile Distribution Model (PDM) Simple model to convert ${ }^{7} \mathrm{Be}$ inventory loss into soil erosion amounts by linking inventory change to the depth profile to derive the mass depth of soil loss. This model is applied to single events over a short period of time.

\section{Appendix 1.1: The Profile Distribution Model}

The exponential depth distribution of ${ }^{7} \mathrm{Be}$ in a soil profile can be described as:

$$
C(x)=c e^{-x / h_{0}}
$$

where $C_{x}\left(\mathrm{~Bq} \mathrm{~kg}^{-1}\right)$ is the ${ }^{7} \mathrm{Be}$ activity at mass depth $x\left(\mathrm{~kg} \mathrm{~m}^{-2}\right), c$ is a constant value and $h_{0}$ is the relaxation mass depth, the depth at above which $63.2 \%$ of the ${ }^{7} \mathrm{Be}$ inventory can be found.

Erosion rates $\left(\mathrm{kg} \mathrm{m}^{-2}\right)$ can be estimated by comparing the ${ }^{7} \mathrm{Be}$ inventories at the sample site, $A\left(\mathrm{~Bq} \mathrm{~m}^{-2}\right)$, to the reference inventory, $A_{\text {ref }}\left(\mathrm{Bq} \mathrm{m}^{-2}\right)$. Where a mass of soil has been lost $(h)\left(\mathrm{kg} \mathrm{m}^{-2}\right)$ changes in the sample site inventories can be represented as:

$$
A=\int_{-h}^{\infty} C(x) d x=A_{r e f} e^{h / h_{0}}
$$

Erosion rate, $h\left(\mathrm{~kg} \mathrm{~m}^{-2}\right.$, negative), can, therefore, be calculated as:

$$
h=h_{0} \ln \left(A / A_{\text {ref }}\right)
$$

Deposition of material is reflected in an excess of ${ }^{7} \mathrm{Be}$ inventory at the sample site with respect to the reference site. The depth of deposition, $h^{\prime}\left(\mathrm{kg} \mathrm{m}^{-2}\right.$, positive), can be calculated as:

$$
h^{\prime}=\left(A-A_{r e f}\right) / C_{d}
$$

Where $C_{d}\left(\mathrm{~Bq} \mathrm{~kg}^{-1}\right)$ is the mean activity concentration of ${ }^{7} \mathrm{Be}$ in the deposited sediment.

The ${ }^{7} \mathrm{Be}$ activity concentration in the eroding sediment at each upslope point, $C_{e}$ $\left(\mathrm{Bq} \mathrm{kg}^{-1}\right)$, can be calculated from the loss of inventory divided by the mass of soil loss: 


$$
C_{e}=\left(A_{r e f}-A\right) / h
$$

The mean activity concentration of soil mobilised from the study area, $S\left(\mathrm{~m}^{2}\right)$, can then be calculated as:

$$
C_{\mathrm{d}}=\int_{S} h C_{\mathrm{e}} d S / \int_{S} h d S
$$

\section{References}

Baumgart, P., Riedel, E., Eltner, A., \& Faust, D. (2016). Soil surface sampling approaches for reliable radiogenic isotope tracer investigations. Soil Science, 181, 82-88. https://doi.org/10. 1097/SS.0000000000000141.

Blake, W. H., Walling, D. E., \& He, Q. (1999). Fallout beryllium-7 as a tracer in soil erosion investigations. Applied Radiation and Isotopes, 51, 599-605.

Blake, W. H., Wallbrink, P. J., Wilkinson, S. N., Humphreys, G. S., Doerr, S. H., Shakesby, R. A., et al. (2009). Deriving hillslope sediment budgets in wildfire-affected forests using fallout radionuclide tracers. Geomorphology, 104, 105-116.

Doering, C., \& Akber, R. (2008). Beryllium-7 in near-surface air and deposition at Brisbane, Australia. Journal of Environmental Radioactivity, 99, 461-467. https://doi.org/10.1016/j.jenvrad. 2007.08.017.

Ioannidou, A., \& Papastefanou, C. (2006). Precipitation scavenging of Be-7 and Cs radionuclides in air. Journal of Environmental Radioactivity, 85, 121-136.

Iurian, A.-R., Toloza, A., Adu-Gyamfi, J., \& Cosma, C. (2013). Spatial distribution of ${ }^{7}$ Be in soils of Lower Austria after heavy rains. Journal of Radioanalytical and Nuclear Chemistry, 298, 1857-1863. https://doi.org/10.1007/s10967-013-2683-8.

Kaste, J. M., Norton, S. A., \& Hess, C. T. (2002). Environmental chemistry of beryllium-7. Beryllium: Mineralogy, petrology, and geochemistry (pp. 271-289). Washington: Mineralogical Soc America.

Kusmierczyk-Michulec, J., Gheddou, A., \& Nikkinen, M. (2015). Influence of precipitation on ${ }^{7} \mathrm{Be}$ concentrations in air as measured by CTBTO global monitoring system. Journal of Environmental Radioactivity, 144, 140-151. https://doi.org/10.1016/j.jenvrad.2015.03.014.

Mabit, L., Benmansour, M., \& Walling, D. E. (2008). Comparative advantages and limitations of the fallout radionuclides ${ }^{137} \mathrm{Cs},{ }^{210} \mathrm{~Pb}_{\mathrm{ex}}$ and ${ }^{7} \mathrm{Be}$ for assessing soil erosion and sedimentation. Journal of Environmental Radioactivity, 99, 1799-1807.

Mabit, L., Meusburger, K., Iurian, A.-R., Owens, P. N., Toloza, A., \& Alewell, C. (2014). Sampling soil and sediment depth profiles at a fine resolution with a new device for determining physical, chemical and biological properties: The Fine Increment Soil Collector (FISC). Journal of Soils and Sediments, 14, 630-636. https://doi.org/10.1007/s11368-013-0834-8.

Porto, P., \& Walling, D. E. (2014). Use of ${ }^{7} \mathrm{Be}$ measurements to estimate rates of soil loss from cultivated land: Testing a new approach applicable to individual storm events occurring during an extended period. Water Resources Research, 50, 8300-8313. https://doi.org/10.1002/ 2014WR015867.

Ryken, N., Al-Barri, B., Taylor, A., Blake, W., Maenhout, P., Sleutel, S., et al. (2016). Quantifying the spatial variation of ${ }^{7} \mathrm{Be}$ depth distributions towards improved erosion rate estimations. Geoderma, 269, 10-18. https://doi.org/10.1016/j.geoderma.2016.01.032.

Schuller, P., Iroume, A., Walling, D. E., Mancilla, H. B., Castillo, A., \& Trumper, R. E. (2006). Use of beryllium-7 to document soil redistribution following forest harvest operations. Journal of Environmental Quality, 35, 1756-1763. https://doi.org/10.2134/jeq2005.0410. 
Schuller, P., Walling, D. E., Iroume, A., Castillo, A. (2010). Use of beryllium-7 to study the effectiveness of woody trash barriers in reducing sediment delivery to streams after forest clearcutting. Soil and Tillage Research, 110, 143-153.

Sepulveda, A., Schuller, P., Walling, D. E., \& Castillo, A. (2008). Use of Be-7 to document soil erosion associated with a short period of extreme rainfall. Journal of Environmental Radioactivity, 99, 35-49. https://doi.org/10.1016/j.jenvrad.2007.06.010.

Shi, Z. L., Wen, A. B., Zhang, X. B., \& Yan, D. C. (2011). Comparison of the soil losses from ${ }^{7} \mathrm{Be}$ measurements and the monitoring data by erosion pins and runoff plots in the Three Gorges Reservoir region, China. Applied Radiation and Isotopes, 69, 1343-1348. https://doi.org/10.1016/ j.apradiso.2011.05.031.

Taylor, A., Blake, W. H., Couldrick, L., \& Keith-Roach, M. J. (2012). Sorption behaviour of beryllium-7 and implications for its use as a sediment tracer. Geoderma, 187-188, 16-23.

Taylor, A., Blake, W. H., Smith, H. G., Mabit, L., \& Keith-Roach, M. J. (2013). Assumptions and challenges in the use of fallout beryllium-7 as a soil and sediment tracer in river basins. Earth-Science Reviews, 126, 85-95.

Taylor, A., Blake, W. H., \& Keith-Roach, M. J. (2014). Estimating Be-7 association with soil particle size fractions for erosion and deposition modelling. Journal of Soils and Sediments, 14, 1886-1893. https://doi.org/10.1007/s11368-014-0955-8.

Taylor, A., Keith-Roach, M. J., Iurian, A. R., Mabit, L., \& Blake, W. H. (2016). Temporal variability of beryllium-7 fallout in southwest UK. Journal of Environmental Radioactivity, 160, 80-86. https://doi.org/10.1016/j.jenvrad.2016.04.025.

Walling, D. E., He, Q., \& Blake, W. (1999). Use of Be-7 and Cs-137 measurements to document short- and medium-term rates of water-induced soil erosion on agricultural land. Water Resources Research, 35, 3865-3874.

Walling, D. E., Schuller, P., Zhang, Y., \& Iroume, A., (2009). Extending the timescale for using beryllium-7 measurements to document soil redistribution by erosion. Water Resources Research 45. W02418 https://doi.org/10.1029/2008wr007143. 
The opinions expressed in this chapter are those of the author(s) and do not necessarily reflect the views of the International Atomic Energy Agency, its Board of Directors, or the countries they represent.

Open Access This chapter is licensed under the terms of the Creative Commons Attribution 3.0 IGO License (https://creativecommons.org/licenses/by/3.0/igo/), which permits use, sharing, adaptation, distribution and reproduction in any medium or format, as long as you give appropriate credit to the International Atomic Energy Agency, provide a link to the Creative Commons licence and indicate if changes were made.

The use of the International Atomic Energy Agency's name, and the use of the International Atomic Energy Agency's logo, shall be subject to a separate written licence agreement between the International Atomic Energy Agency and the user and is not authorized as part of this CC-IGO licence. Note that the link provided above includes additional terms and conditions of the licence.

The images or other third party material in this chapter are included in the chapter's Creative Commons licence, unless indicated otherwise in a credit line to the material. If material is not included in the chapter's Creative Commons licence and your intended use is not permitted by statutory regulation or exceeds the permitted use, you will need to obtain permission directly from the copyright holder.

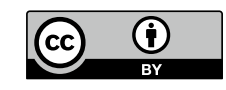

